\title{
Article \\ Barriers to Offsite Construction Adoption: A Quantitative Study among Housing Associations in England
}

\author{
Andrew Agapiou
}

Citation: Agapiou, A. Barriers to Offsite Construction Adoption: A Quantitative Study among Housing Associations in England. Buildings 2022, 12, 283. https://doi.org/ 10.3390/buildings12030283

Academic Editors: Pierfrancesco De Paola, Francesco Tajani,

Marco Locurcio and Felicia Di Liddo

Received: 20 January 2022

Accepted: 28 February 2022

Published: 2 March 2022

Publisher's Note: MDPI stays neutral with regard to jurisdictional claims in published maps and institutional affiliations.

Copyright: (C) 2022 by the author. Licensee MDPI, Basel, Switzerland. This article is an open access article distributed under the terms and conditions of the Creative Commons Attribution (CC BY) license (https:// creativecommons.org/licenses/by/ $4.0 /)$.
Department of Architecture, University of Strathclyde, James Weir Building, 75 Montrose Street, Glasgow G1 1XJ, UK; andrew.agapiou@strath.ac.uk

\begin{abstract}
Housing associations (HAs) play a pivotal role in the delivery of affordable homes and, therefore, offsite construction could be beneficial in alleviating the crisis. Existing literature has focused on the perceptions of the housing sector at large towards offsite construction (OSC), particularly private housebuilders. This research addresses this gap in the literature. This paper explores the perceived barriers of using OSC through a survey of the largest HAs in England [ $n=69]$, and how these compare with the perceptions within the wider housing sector. The evidence from this research indicates cost-related barriers are perceived to be the most significant barriers to OSC use for HAs, followed by the capacity of suppliers and end-user preferences for traditional construction. The perceived barriers of those with experience are aligned with the OSC literature, whilst the responses of those without direct experience suggested heightened concerns towards the key barriers. A conceptualised feedback model is proposed to monitor, capture knowledge and share best practice as HAs commit to accelerating project delivery through strategic partnerships with offsite manufacturing firms, local authorities at a local/regional level, that leverage the high-value, high-impact transformation of the housebuilding sector in tangible terms of efficiency, cost, and material savings.
\end{abstract}

Keywords: barriers; housing associations; offsite construction; perceptions

\section{Introduction}

Since the housing crisis of 2008, the delays in housing starts and completions has resulted in a widespread housing shortfall in the UK that has challenged policymakers and developers to re-evaluate their position on modern methods, acceleration techniques, and technological opportunities [1]. Whilst traditional construction continues to serve as the primary mode of new housing fulfilment, recent evidence suggests that in order to meet the future needs of UK households and fulfil a more diversified spectrum of housing solutions, modern methods, and offsite techniques are of critical importance [2,3].

Alternative methods to traditional construction are increasingly being explored as a way to address the housing crisis in England. This is demonstrated by the recent parliamentary inquiry into MMC and Homes England's Strategic Plan in which developers receiving funding for developments of over 50 units must incorporate some form of MMC [4,5]. In England, up to 340,000 houses are needed per year to meet housing demand [6], however, only 164,390 new homes were completed in the England during 2018 [7]. Of these, approximately $17 \%$ were completed by HAs and less than $2 \%$ by local authorities, showing HAs is crucial in the delivery of affordable housing [8]. With 145,000 affordable properties required in England per year [6], based on recent performance, HA development will be critical to achieve the required output.

As a central agency responsible for providing adequate and quality housing to residents throughout a given region, UK housing associations (HAs) are defined as 'not-forprofit social landlords that provide homes and support for around 6 million people all around England' [9]. With pressure to accelerate the rate of delivery for such social housing 
solutions that are affordable and high-quality, the viability of offsite manufacturing is a pragmatic consideration that must be weighed, assessed, and considered for meeting future needs. Whilst a growing body of literature has critically explored the advantages and potential limitations of prefabricated, modular, and offsite construction practices, the lack of consensus and dependency upon traditional methods of construction have led to conceptual and ideological gaps that are continuing to threaten the long-term viability of this modern solution.

The extant research has largely focused on the experiences of the housing sector at large towards offsite construction, particularly private housebuilders. Currently, there is a dearth of research into the potential for adopting offsite solutions within HA developments, notwithstanding the 2017 report published by the University of the West of England which assessed the evidence for the take-up of prefabrication in the social housing sector in England [9]. For HAs, organizations that are confronted with a need to accelerate the rate of construction and mitigate the longstanding reputational threats of low-quality, low-efficiency housing, the practical opportunities of offsite housing are significant.

There is a growing interest in OSC from HAs, demonstrated by investment in their own manufacturing facilities $[10,11]$ and research projects, such as Gateshead Innovation Village (Home Group 2019). Of the top 50 biggest developing HAs, 23 expect to complete homes using MMC in 2019/20, an increase from 16 in 2018/19 [12,13]. Despite this, OSC uptake nationally for HAs is low. If uptake is to increase, the perceptions of HAs towards OSC need to be understood, including the perceived barriers to OSC adoption. Currently, there is no literature focusing on these perceptions; a gap that this research begins to address.

Therefore, the aim of this research is to explore the perceived barriers within housing associations towards the use of OSC and how these compare with the perceptions within the wider housing sector. The objectives of the study are three-fold: (i) to critically review perceived barriers for OSC in the housing sector; (ii) to identify perceived barriers among HAs in using OSC methods and how these compare with the perceptions of the wider housing sector; and (iii) to explore whether experience in OSC methods affects perception of OSC usage.

\section{Housing Associations and Offsite Housing}

Despite an increasingly robust history in UK housing deliveries, offsite construction is often confronted with industry resistance, particularly in public housing sectors where government officials are challenged to justify value for money. Rowley et al. [14], for example, have observed that the delivery of affordable social housing by government agencies is threatened by a variety of concerns, including changing housing prices, economic conditions, demand-side variables (e.g., employment, wage growth, investment yields) and supply-side variables (e.g., land supply, construction efficiency, labour costs, planning regulations). The resultant bullwhip effect in housing supply, a phenomenon initially observed by Wheaton [15] in relation to private sector housing fulfilment, results in an over-under supply model that, whilst progressing towards natural equilibrium, is at risk for cyclical changes and delays. Therefore, MacAskill et al. [16] argue that where the primary 'goal of affordable housing is to achieve equilibrium', thereby eliminating the need for a waiting list or stricter qualifications, gap mitigation strategies (e.g., housing transfer, expedited construction methods) are needed to overcome systemic gaps in the housing supply. Central to the primary economic advantages of offsite housing identified by the NAO [17] is the volumetric housing benefits that provide housing associations with distinct advantages, including earlier rent recovery, a shorter borrowing period, less project delays, and less on-site inspections. Forecasting upwards of $80 \%$ fewer project defects and upwards of $80 \%$ compression of the time of delivery, the findings presented by Miles and Whitehouse [18] also confirmed a direct benefit to the housebuilder and a significant, broader social impact due to the accelerated delivery of high-quality, often affordable housing solutions. As developers weigh the functional and systemic advantages of offsite construction, Barton et al. [19] confirm that higher quality, higher efficiency prefabrication 
will not only reduce the operational costs and emissions of the property over time, but will prescribe a future structural standard that dramatically improves the broader standard of practice in the construction industry.

\subsection{Literature Review}

A cursory review of the offsite construction literature reveals a dearth of academic research into the perceptions of HAs specifically towards OSC. Only Kempton and Syms [20,21] have explored this, focusing on the perceived impact on maintenance and asset management. To address the first objective, the literature focusing on perceptions towards OSC within the housing sector was identified and reviewed. Literature was obtained through searches on online databases, including Google Scholar, ARCOM, Science Direct and Ingenta Connect. Terms, such as "offsite construction", "off-site manufacture", "prefabrication", "modern methods of construction" were used in conjunction with "housing association", "housing" and "residential". For brevity, only UK based or UK concerned literature was included for detailed examination. The literature search was expanded through snowballing; reviewing the citations and reference list of each paper and further literature in which the original paper has been cited [22]. The literature predominantly consisted of journal articles, conference papers, and industry generated reports. Abstracts and executive summaries were read to ascertain whether the literature contained research into perceptions. Those that did were thoroughly examined to establish the perceived barriers to OSC use, in order to address the first research objective.

The literature contained a larger range of perceived barriers within the wider housing industry, with 24 themes identified. Figure 1 illustrates that the results were multimodal with four barrier themes, each featured in $53 \%$ of the literature reviewed: industry perceptions, customer perceptions, skills requirements, and cost.

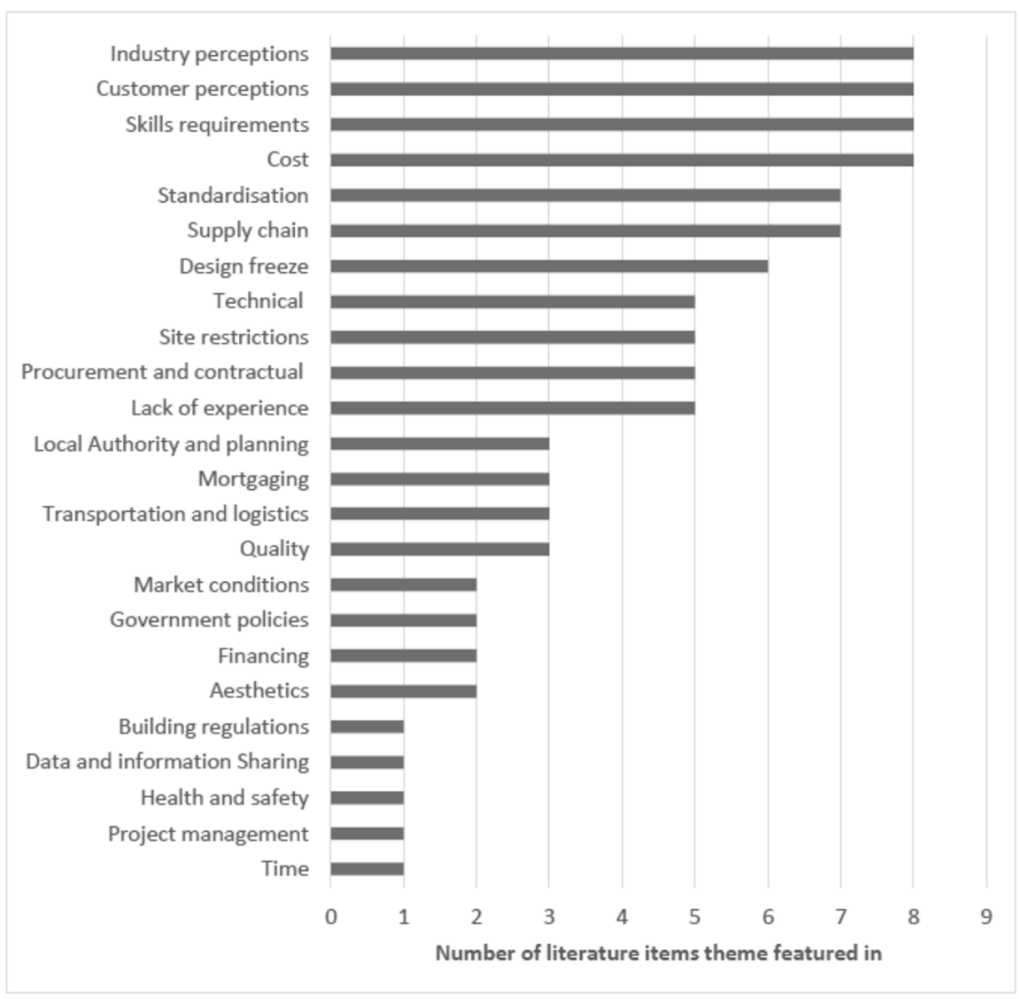

Figure 1. The number of pieces of literature on each barrier theme is featured within the literature.

The section below discusses the level of importance attributed to these four key barrier themes, with comparisons made between their significance within the wider OSC housebuilding literature and studies related to housing association perceptions. A critique 
of the wider body of knowledge is also provided, highlighting both methodological gaps and weaknesses within the OSC housebuilding literature, and how this may limit the scope of direct comparison with the research findings. The theoretical gap is then defined as the basis for further consideration and exploration.

\subsubsection{Industry Perceptions}

The attitudes of the housing building industry towards OSC are a frequently occurring barrier; however, it is not considered to be highly significant, ranking sixth out of seven most important barriers to the use of prefabrication [23]. In Pan et al. [24,25], "Attitudinal barriers due to historic failures" was selected by $11 \%$ of participants as being one of the three most significant barriers to the use of offsite-MMC. This is supported by $[20,21,26]$, who identify that previous negative experience with non-traditional construction methods has fueled tarnished perceptions and negative attitudes towards OSC. The perceived risk of adopting new processes and systems was a highly ranked constraint in [27], selected by $24 \%$ of participants. In Pan et al. [24,25], "Reluctance to innovation" was selected by $11 \%$ of participants as being one of the three most significant barriers to using modern methods of construction. Conversely, "Want to modernise" was presented as a driver for investing in MMC in [28] and selected by 39\% as a driver. However, [28] reveal that the majority of housebuilders and HAs considered themselves "Followers" or "Late adopters" to MMC. Only 3\% of HA participants consider their organisation to be "Market leaders" [29].

\subsubsection{Customer Perceptions and Attitudes}

Public attitude is also considered an important barrier to prefabrication uptake by housebuilders [23], supported by [27], where it ranks as the joint fourth biggest constraint. "Buyer reactions" is also the third most selected main barrier to modular construction [29]. This is supported by [20,21,29], who identify that previous negative experience with nontraditional construction methods has fuelled tarnished perceptions and negative attitudes towards offsite construction methods. However, "Culture resistance-poor public perception" is a lowly ranked barrier in [30], jointly ranked 17th in significance out of 20 perceived barriers. "No demand for prefabrication" is the lowest-ranked barrier affecting prefabrication uptake in [31].

\subsubsection{Skills Requirements}

The need to address skills shortage is frequently cited as a significant perceived barrier to the wider take-up of OSC. For example, $87 \%$ of participants in [31] considered this to be a significant barrier, making it the second highest selected barrier. It was also considered significant by participants in [29], where it was the fourth most selected main barrier to modular construction.

Dave et al. [27] highlighted the perceived concerns over the lack of training and experience of builders, contractors, developers, and designers, including architects and engineers. However, skills requirements are not a significant perceived barrier according to [28], in which only $6 \%$ of participants considered it to be a barrier to MMC uptake by developers. This is supported by [24,25], in which only $11 \%$ of participants selected "Skills shortage" within the top three barriers to offsite-MMC, and [23] where it is considered the least important out of the seven presented barriers for prefabrication.

\subsubsection{Cost}

Cost features function equally as a driver and barrier within the OSC literature. The two most important barriers from the [23] housebuilders survey were "More expensive than masonry" and "High upfront capital cost". These two barriers are supported in [31], where they are considered significant constraints by $64 \%$ and $71 \%$ of participants, respectively. Cost-related barriers were also the two most frequently selected within the top three barriers in [24,25]: "Higher capital cost" was selected by $68 \%$ of respondents, and "Difficult to achieve economies of scale" was selected by $43 \%$ of respondents. "Extra expenses" was 
the most frequently selected barrier affecting prefabrication in [30]. Increased capital cost is shown as the main barrier to the use of modular construction for both housebuilders and Has in [29].

\subsection{Critical Appraisal of OSC Housebuilding Literature}

The use of questionnaire surveys which characterise much of the extant literature discussed is a valuable method to help understand the barriers to OSC as perceived by the UK housebuilding industry. To further understand how these barriers are operationalised in the public sector and to explore how they might be overcome, it is necessary to ascertain the views of Has and compare these with perceptions seen in the wider housing building sector. There is a need to exercise caution when considering such a comparative exercise, as there is limited information on methodology, responses received, the format of questions and the weightings given to responses.

For example, very limited information is provided by $[20,26,29]$ about how suitable samples were decided and survey participants or interviewees selected. In contrast, [28,29] provided greater detail on how participants were selected through purposive sampling to ensure views from across the organisation were represented and to ensure participants had the appropriate level of knowledge. The information provided on samples, or lack of, must be referred to when determining whether results are representative of a population. The sample size is also a limitation for all research in which a questionnaire was the primary data collection method [23-25,27,32,33]. In addition to differences in research aims and targeted participants, the specific type of non-traditional construction being researched in the literature varies between MMC, OSM, OSC, prefabrication and modular. This should also be considered when comparing results. All the identified research has been conducted at the higher level of classification of the construction method. Research into perceptions of lower-level classifications, such as volumetric, panelised systems and pre-assembled sub-components should be conducted to evaluate the differences between the perceived barriers for each of these methods.

\subsection{The Theoretical Gap}

After a thorough literature review on the perceived barriers to adopting offsite construction, the authors identified the theoretical gaps in this topic. While the most frequently cited perceived key barriers to the adoption of OSC within the literature were related to industry and customer perceptions, cost, and skill requirements, the review also showed a lack of research into HA perceptions towards OSC, with only NHBC Foundation (2016) providing some results for HA participants independently of private housebuilders. In summary, the differences in results seen in NHBC Foundation (2016), between HAs and private housebuilders, indicates that perceptions are not consistent between the two populations.

\section{Research Methodology}

To achieve the research objective, firstly a review of the literature on the topic was conducted and related articles were reviewed. In order to achieve the second and third objectives, a quantitative survey was used to explore the perceptions of housing associations towards the barriers to OSC usage in England. Questionnaires are suited to the exploratory nature of this research [34] and have been commonly deployed within OSC research to establish perceptions (e.g., [21,24,25,28]).

An online platform, Smart Survey, was used to distribute the questionnaire survey, due to the time advantage of automated data collection, cost, and environmental benefits compared with a postal survey [35].

The 24 barrier themes identified from the literature review were thematically coded. These were used to develop questions for primary data collection and analysis of questionnaire results, allowing for additional categories to be added and refined in response to the data collected [36]. The literature also provided secondary source data which has been used for triangulation during the analysis of the primary data. Further research, using different 
primary data collection methods, such as interviews, were also considered to improve the process of triangulation.

\subsection{Questionnaire Design}

The survey tool was developed with the aim of investigating the perceived barriers of using OSC through a survey of the largest HAs in England and how these compare with the perceptions within the wider housing sector. The questionnaire survey included four sections:

Section 1: General information about the respondent and the extent to which they have had direct experience of different types of OSC systems on UK housebuilding developments.

Section 2: In the second part of the questionnaire, five-point Likert scale questions were initiated to measure HA professionals' perceptions towards the 24 barrier themes listed in Figure 1.

Section 3: In the third part of the questionnaire, HA professionals were asked to select the three most significant barriers militating against the adoption of OSC methods on UK housebuilding developments from 24 options listed in Figure 1.

Section 4: in the fourth part of the questionnaire, HA professionals were asked to select the types of OSC systems most beneficial for housing association development projects, ranging from panelised, volumetric, hybrid, through to modularised systems.

On reflection, these questions did not allow participants who felt they could not give an answer to bypass this question, which may have introduced bias by requiring the participant to make only three selections [36]. Additionally, responses only show the three most selected barriers from the options given; participants may consider other reasons to be the key barriers [36]. To address this, an "Other" option was provided to allow additional reasons.

\subsection{Sample Design}

It is beyond the scope of this research to use a census study; therefore, two sample sets of HAs were established to focus the study.

It was decided to target HAs who are most likely to have experience in OSC, mirroring the approaches of [23-26]. To target experienced developing HAs, organisations featured in the 'Inside Housing Top 50 Biggest Builders 2019' were used as a non-random purposive sample [12,36].

HAs identified through the literature review as experienced or having previously shown interest in OSC, formed the second sample; a number of which are not present in the Top 50. It is understood that results from these samples cannot be inferred into all HAs, as these samples contain HAs most established in development or OSC usage. Consequently, the perceptions of these organisations may differ from HAs with limited experience in these remits; an area requiring future research. To establish target participants, employees of the organisations in the sample sets were identified through online searches. Organisational websites, news articles, and LinkedIn were used to identify job roles and valid email addresses for $180 \mathrm{HA}$ employees. Those with senior or managerial positions within development, construction, technology, design, innovation, commercial, property services, sustainability, and project management were targeted. Additionally, network contacts were used to identify employees of HAs within the two sample populations. It is acknowledged that there is an inherent bias in the process of identifying recipients for the questionnaire.

Assumptions had to be made regarding job titles and listed experience for LinkedIn profiles to determine whether the employee should be a targeted recipient, such as whether a project manager was involved in construction project management. The online search was heavily dependent on the detail of information each organisation publicly shares. Where information was available on employees and job roles, this was often provided for a whole team. Therefore, some HAs in the sample sets had multiple targeted participants where such information was available, the highest being twelve, whereas some only had two. A larger number of targeted employees were also identified for some HAs through 
network connections. Consequently, some organisations had a greater opportunity to be represented than others and this bias may be reflected in the results. To alleviate the risk of this bias impacting results, demographic information was collected to understand the types of participants who completed the questionnaire, such as the operating regions of the organisation.

\subsection{Survey Response Rate}

In total, 69 responses were received, representing a response rate of $38 \%$ based on the 180 targeted participants. A response rate around this figure is reasonable in comparison with similar surveys conducted by $[24,25,31]$, which set a benchmark response rate between $31 \%$ and $36 \%$ [34].

\subsection{Triangulation of Results}

The original intention was to explore views of HA through both a quantitative and qualitative approach. It was anticipated that semi-structured interviews with senior managers from the larger HA developers in the UK would provide a source for triangulation for the questionnaire results. Due to unforeseen circumstances, it became difficult to secure interviews in the required time frame. Therefore, interviews were not included in this research, with a greater focus given to the questionnaire. Interviews would have been beneficial in providing depth to the questionnaire results and obtaining more intricate detail, overcoming criticism of using a questionnaire in isolation [30]. To mitigate this weakness, comment boxes were used throughout the questionnaire to collect optional further detail from participants, as recommended by [37]. This was beneficial, as 27 comments were received, adding additional value to the responses. It would have not been suitable to consider interview findings as representative of typical HA attitudes, but they would have helped with the triangulation of the questionnaire results to examine the accuracy of the datasets [34]. Consequently, questionnaire results have been triangulated with the existing literature only. This is a limitation of this study and future research should conduct interviews with HA professionals to add depth to and verify the questionnaire results. However, as seven sources directly address the ranking of perceived barriers to OSC, triangulation between the primary data collected and the extent OSC literature is suitable.

\subsection{Survey Results and Findings}

The forgoing section presents the results from the questionnaire survey of housing association perceptions of the barriers towards adopting offsite construction.

\subsection{The Demographics of the Survey Respondents}

The demographic information was collected to allow understanding of the type of participants who responded and determine whether these are representative of the targeted sample that the questionnaire was sent to. Demographic information on location and experience in OSC were selected as appropriate to use for results analysis due to the size of the subsets of these populations.

As seen in Figure 2 the South East and West Midlands were the most represented regions that respondents work in. The Northern regions (Yorkshire and the Humber, North East, and North West) and South West were significantly under-represented. To determine how representative the results are for the sampled population, the operating regions of the targeted sample and the respondents were compared. As shown in Figure 3, the percentage of respondents whose organisations operate in the South East, East Midlands, West Midlands, and East is much greater than the percentage of the targeted sample HAs who operate in these regions. This shows bias may have been introduced due to a higher chance of a direct contact of the researcher completing the questionnaire and forwarding to their own network than those whose details were established from online searches [37]. 


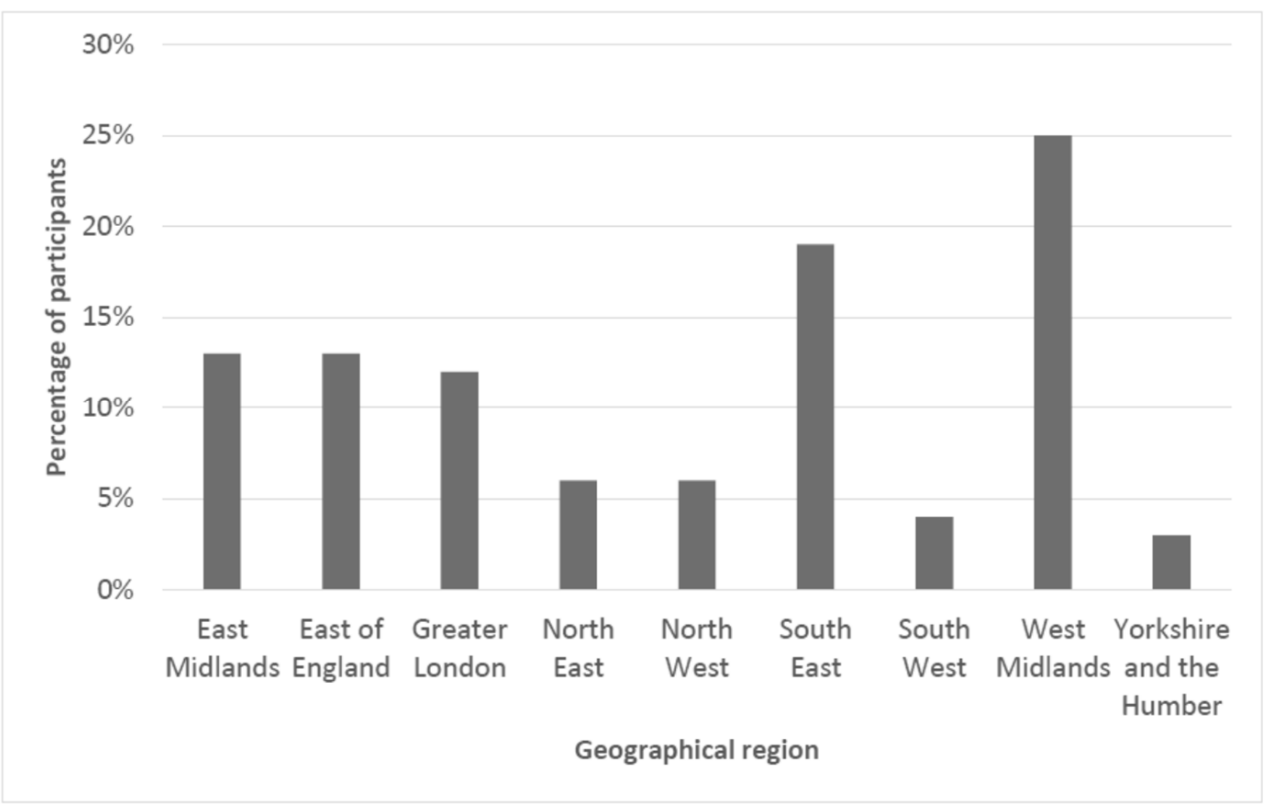

Figure 2. The distribution of geographical regions worked in by respondents.

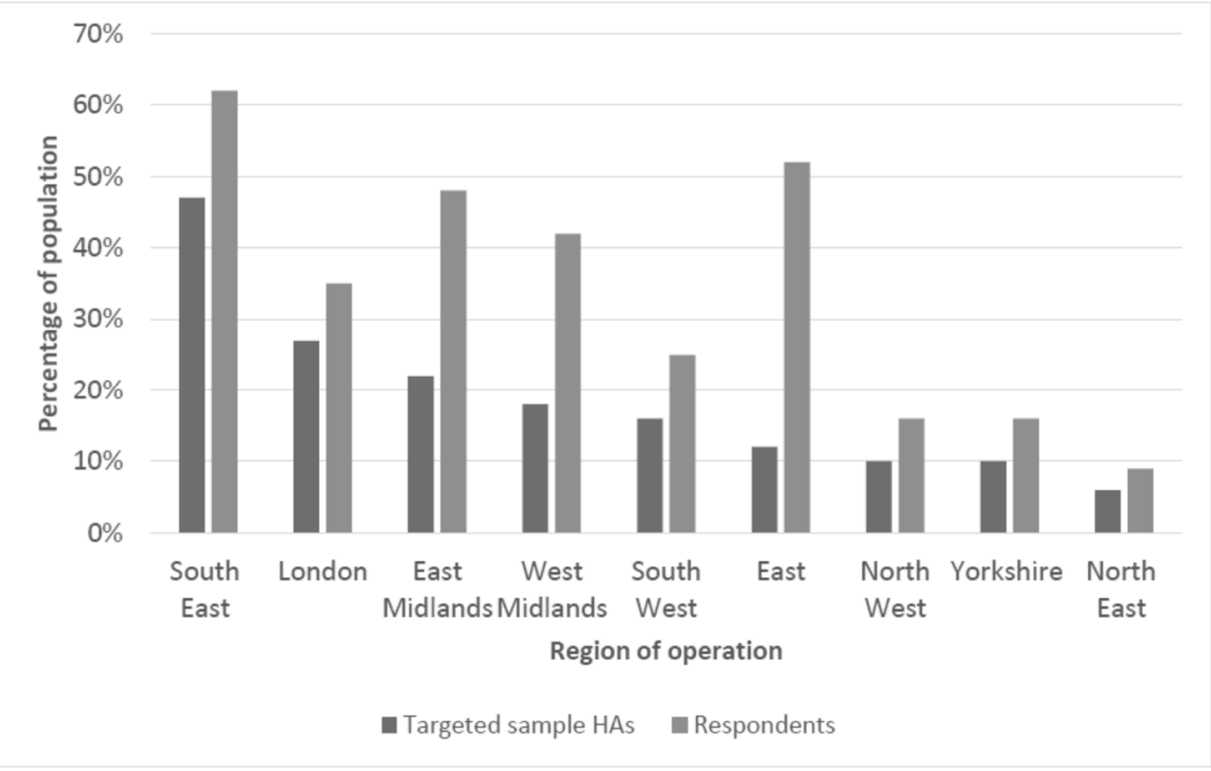

Figure 3. Comparison of the distribution of operational regions of the targeted sample, and those who responded.

\subsection{Experience in Offsite Construction Methods}

Demographic information on whether a participant has direct experience in OSC methods is applied during data analysis to explore whether perceptions towards OSC are influenced by direct experience, fulfilling research objective 4 . A majority, 77\%, of respondents have direct experience in at least one OSC method. Seven participants have experience in all five OSC methods presented. The methods experienced are shown in Figure 4. 


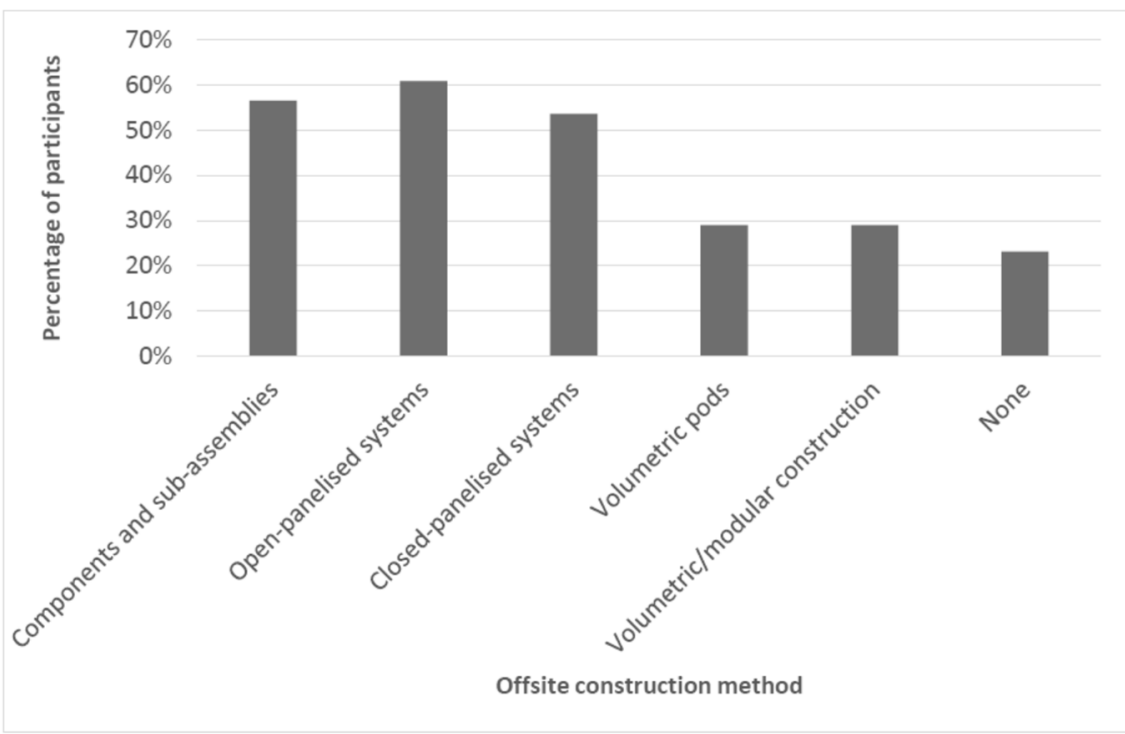

Figure 4. Distribution of experience in given types of the offsite construction method. (Direct experience was stated as "You have been directly involved in a project where the following offsite construction methods were considered or used").

\subsection{Perceived Barriers to Offsite Construction}

The findings from the questionnaire survey indicated the inability to achieve economies of scale and increased project costs were the two most selected barriers (both $35 \%$ ), closely followed by increased capital cost $(33 \%)$, the capacity of suppliers $(32 \%)$ and end-user preference for traditional construction methods $(30 \%)$. The results correspond with the perceptions seen in the literature. The most selected cost-related barriers support the results of [31] in which cost was considered the third highest important decision factor to OSC use. In [24-26], an increased capital cost was considered the main barrier by private housebuilders and housing associations, respectively. Difficulty in achieving economies of scale was also the second most selected barrier in [24,25]. The fourth and fifth most selected barriers also align with [29], in which the capacity of suppliers was the second most selected barrier, and customer preference for traditional construction was the third. Equivalent barriers were not presented in $[24,25]$.

\subsection{The Impact of Experience on Perceptions towards Barriers}

The responses from the population with experience are more in keeping with the results of [24-26] than the population without direct experience. The inability to achieve economies of scale" is the second most selected perceived barrier by both populations, however, there is a noticeable difference between the two for most perceived barriers towards OSC usage, as shown in Figure 5.

Figure 6 indicates that the perception of those with experience aligns with the findings within the extant OSC literature. In [24,25], only 7\% of housebuilder participants considered it the third most significant barrier and in [38], although it was the fourth highest perceived concern, it was only the ninth most selected top barrier out of 15. Similarly, "Transportation limitations", the seventh most selected barrier for those without experience $(11 \%)$ and 12 th for those with (19\%), has the second largest divergence in perceived barriers.

Again, those with experience agree with [24-26] in which transportation and logistics are considered significant drivers by only $7 \%$ and $9 \%$ of participants, respectively. These both show that those without experience may have inflated concerns towards these barriers. Without further quantitative research into the reality of these barriers, it is not possible to ascertain whether these perceptions are justified. Increased project costs are the most selected barrier for those with experience, however, it only ranked sixth for those without experience. Although there is not an equivalent barrier presented in [24-26], increased 
costs compared with traditional methods was the highest-ranked barrier by housebuilders in $[23,31]$. This suggests that those without experience are not aware of the full extent of implications on cost when using OSC for a project. The capacity of suppliers/manufacturers is the most selected barrier for those without experience and the fourth for those with experience. In [29], this is also highly ranked by HAs; the second most selected top-three barriers. In $[24,25]$, conversely, only $11 \%$ of private housebuilders perceived this to be in the top three most significant barriers, placing it eighth out of 17 barriers. This difference between the literature may be attributed to two causes: HAs face greater difficulties in securing a supplier due to supplier capacity, or that capacity has become a greater barrier over the last decade.

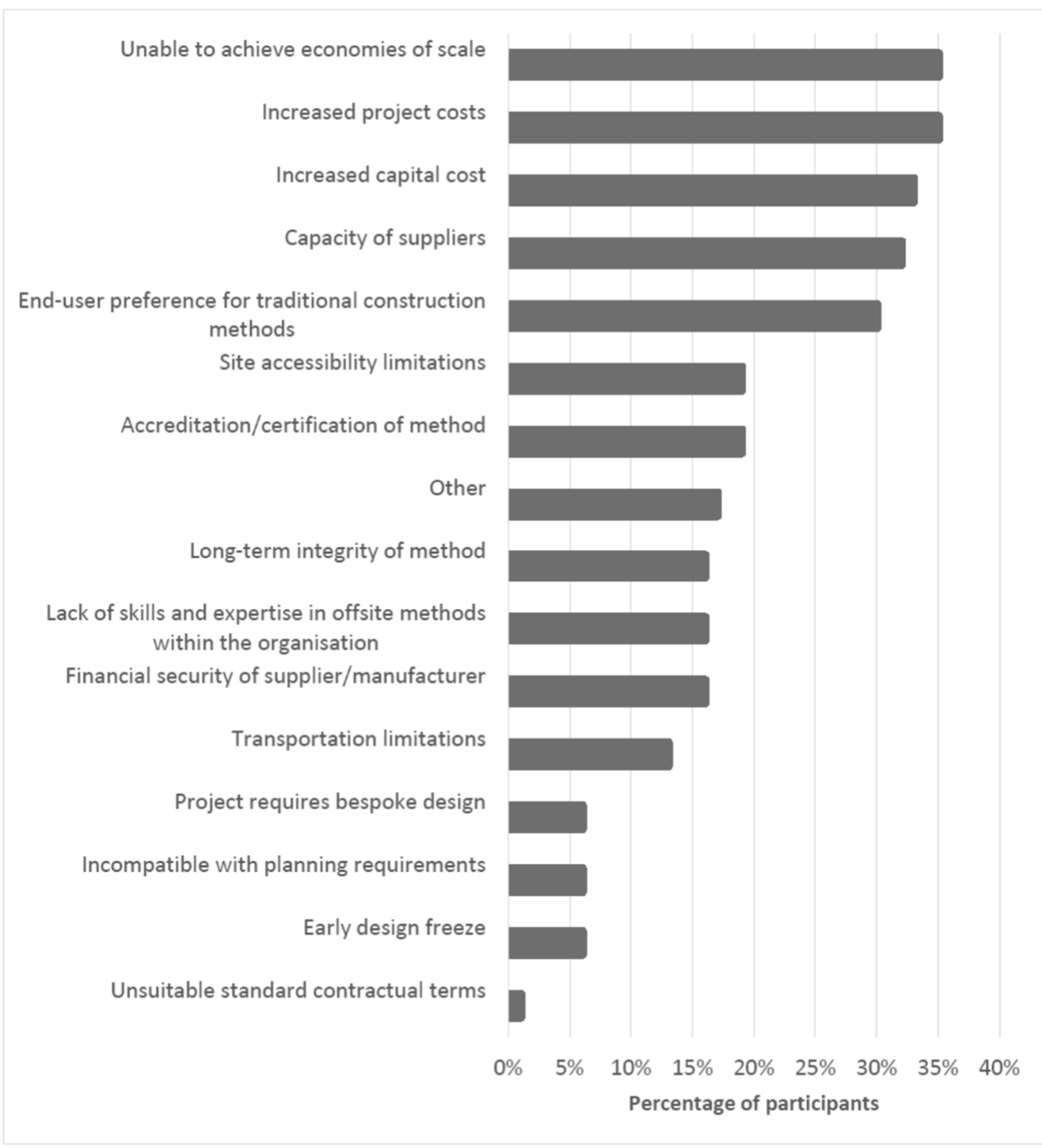

Figure 5. The three most significant barriers to using OSC methods on a project. 


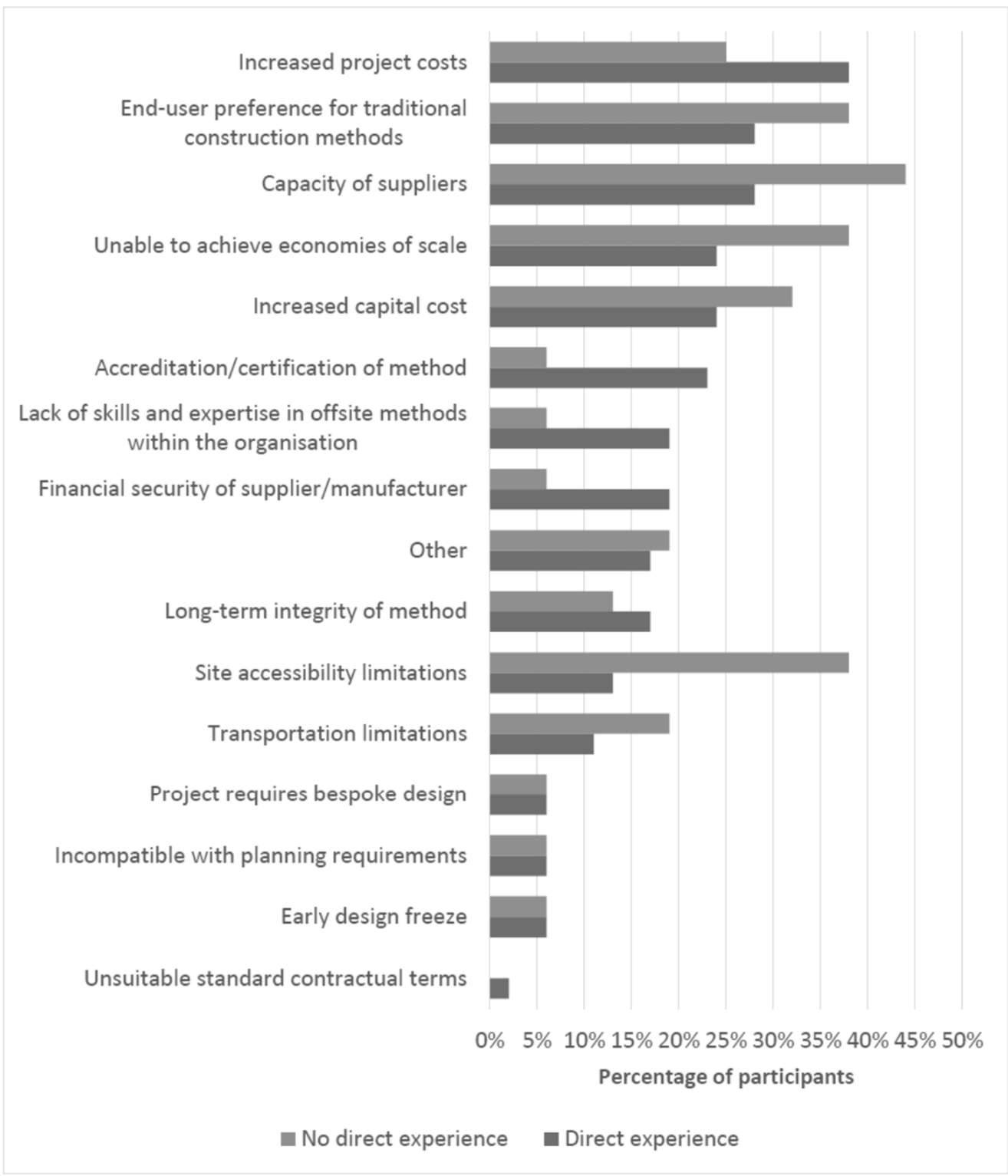

Figure 6. A comparison of the frequency at which respondents considered a barrier to be a top-three biggest barrier between those with direct experience in OSC methods and those without.

\section{Discussion}

The quantitative survey results reveal cost-related barriers to be the most perceived significant barriers to OSC usage for HAs, followed by the capacity of suppliers and end-user preferences for traditional construction. These results correspond with the literature which presented the perceptions of the wider housing sector. The results also revealed noticeable differences in the perceived barriers between those with experience and those without. The perceived barriers of those with experience are aligned with the OSC literature, whilst the responses of those without direct experience suggest inflated concerns towards barriers. The survey comment box also allowed respondents to elaborate on and share additional insight into the perception of the key barrier to adopting OSC, and how the barriers themselves could potentially be addressed. These comments provided nuance and richness to quantitative survey responses and helps to probe the respondents' views on the most influential barriers affecting the adoption of OSC in housebuilding. Overall, 27 comments were received. Of these, 8 comments directly addressed the comparisons between OSC and traditional methods of construction and 19 comments covered perceptions of the most significant barriers to the wider adoption of OSC in the UK housebuilding sector. 
The analysis of free-text comments revealed a clustering of views around the costs associated with the introduction of OSC methods, the industry's reluctance to innovate, the risk-averse nature of the housebuilding sector, customer perceptions, and the role of local authorities in facilitating the transition from traditional on-site construction to offsite construction methods.

\subsection{The Comparison between OSC and Traditional On-Site Methods}

Many of the respondents felt that OSC could be cheaper if done at scale. One HA developer observed that 'there is no difference between offsite and traditional, other than the time savings, without the economies of scale'. Consequently, without securing economies of scale, OSC appears more expensive than traditional construction, and riskaverse housebuilders are unwilling to engage because their existing delivery models generate healthy profits. Although several survey respondents saw significant benefits in OSC in the longer term, there was concern at being the 'one to stick their neck out' and 'taking all the risk'. Without committed investment into developing offsite capabilities, including factories and digital transformation, the capacity of the OSC supply is constrained. Yet without increased volume, the individual unit costs are uncompetitive compared to traditional methods and are thus unattractive to developers and homebuyers. Whilst there is clearly a need and demand for more homes, the various other barriers we have discussed influences market confidence and acts as a hindrance to committed investment.

\subsection{The Significant Barriers to the Wider Adoption of OSC in the UK Housebuilding Sector}

The reluctance of the housebuilding industry to modernise has been cited by others [38], and our participants from the housing association sector, perhaps surprisingly, agreed. They felt that housebuilders are 'historically averse to taking innovative' steps and are heavily committed to existing supply chains, relying on 'archaic' construction processes which they feel are 'tried and tested'. Therefore, they are 'very much wedded to brick and block' and 'getting them to change is incredibly difficult'. This hostility to change is associated with risk management, particularly as current business models already provide significant profits, and private housebuilders are cautious of trying to 'fix something that isn't broken'. The housebuilders' own reluctance to innovate was seen as a greater influence on OSC uptake than that of social perceptions, with the industry using traditional consumer preferences as an excuse for a lack of investment. The author in [38] and others have warned that modernisation may become essential, particularly in terms of the labour market and the risks of Brexit.

Regarding the different processes of design, the housebuilding associations representatives suggested that there should be more collaboration between the different parties involved. Such collaboration could enable greater diffusion of knowledge around OSC.

HA developers were keen to be involved in decision-making earlier in the planning process, to involve the supply chain and develop plans and proposals around the capabilities available. Most participants emphasised the need to address end-users. Participants from the HA development sector suggested the use of digital tools, which not only provide opportunities to share information but also to visualise final outputs, challenging historical perceptions of poor design quality. All of these options are technically feasible, however, the main limiting factor at present is a lack of an opportunity space to bring together the various parties and promote OSC housing to end-users.

There was a remarkable consensus between the various participants about the possible options for overcoming the barriers discussed above. HA developers argued that local authorities should be doing more by engaging in more direct building and procurement of OSC homes. They felt this tied into the fact that 'There is obviously a lot of pressure on local authorities to deliver housing growth', and that 'there is enough housing need in almost every local authority in England for them to have their own factory' to build OSC houses. Whereby traditional housing favours design-build solutions, offsite construction offers the unique opportunity to actively plan, diversify, and integrate modern technologies 
and structural innovations into a regional design platform [39]. Relying upon advanced and technological skill sets that are steeped in innovation and adaptive design, modern manufactured homes will be developed by skilled workers with advanced degrees, clear visions, and adaptive structural solutions [39]. Whilst the justification for the adoption of new offsite methods is likely to be predicated on a variety of influences and performance measures, the emergent platform of high-performing case histories and successful integration outcomes is offering a justified frame of industry knowledge for both reference and integration. Accordingly, to demonstrate the evolving proposition of modular, prefabricated, and offsite construction technologies in the UK, it is important to weigh the evidence from empirical evidence and ongoing case studies that reflect the systemic, structural, and developmental opportunities and challenges encountered during recent years.

\subsection{Strategic Partnerships to Increase the Prevalence of OSC in HA Developments}

Whilst much of this and prior research in this field seems to propose that housing association expectations and demands (or end-user preferences) are a leading cause of resistance to prefabrication, another conclusion can be drawn from the juxtaposition of recent housing association cases and industry innovation: the traditional construction industry is perpetuating the barriers to change. Ultimately, this transition is about formative, functional, and skills-based hurdles which much of the traditional industry is likely to resist. The loss of revenue due to offsite construction, for example, will have severe consequences for traditional home builders. Site-specific trades related to framing, structural supports, and utilities (e.g., electrical, plumbing) will no longer play a central role in the delivery of each individual home. Instead, a paradigm shift from multi-tiered to project-specific contracting will evolve as residential builders rely increasingly heavily upon specialised labour and strategic partnerships with offsite firms. From local partnerships with HAs to manufacturing innovations and bespoke facility development, these skills transition away from one-off residential development to integrative, modular solutions that can be adapted to systematically improve the process of residential construction.

As HAs are not looking at offsite construction as a one home solution and are targeting larger-scale developments, strategic partnerships with offsite professionals, such as those exemplified by, for example, the Home Group, LoCal, and Swan, have the potential to significantly improve the overall cost basis of the structural delivery process, eliminating many of the intermediary costs and waste streams that permeate the traditional construction industry. There is a recognition that local authorities could influence the market if sites could be aggregated to create a scalable pipeline, but this would require support in terms of coordination and incentives to encourage local authorities to limit the market to specific technologies. Predicated upon a foundation of what Hopkin et al. [40] characterise as organisational learning, the transition amongst housing associations away from traditional methods and towards modern construction methods and offsite solutions are increasingly dependent upon justified, purposeful, and experiential integration of new capabilities. Networking effects, for example, encourage housing associations to transfer tacit knowledge across structural boundaries, encouraging behavioural modifications on the basis of direct expertise or emergent innovations [40].

From delivering affordable housing to under-developed or growing areas to rehabilitating existing sites and brownfield spaces, the accelerated rate of structural delivery, high-quality housing, and sustainable residential solutions have the potential to fundamentally alter the nature and focus of housing association strategies. In a multi-case study report on various responses to the volumetric housing crisis in the UK, [39] reveal that critical hurdles, such as regulatory and political ambiguity, stakeholder resistance, and technological gaps have continued to delay the widespread adoption of offsite solutions. However, when coupled with other triggers and enabling events, there are several pathways to improved offsite construction that will translate the examples presented by LoCal and Swan into market-leading examples for an industry that continues to be confronted by unresolved delays and systemic challenges. 
BIM and Digitization: Under the Construction 2025 strategy, government commitments of $50 \%$ faster construction delivery, 33\% lower costs, and 50\% lower emissions require a fundamental revision to existing standards of practice in the traditional construction industry [40]. BIM and smarter construction design solutions prioritise real-time tracking, site-system management modelling, and component-based construction practices that not only justify offsite solutions but compel traditional firms to explore new ways of conducting business and executing their residential deliveries [41].

Building Performance and Sustainability Goals: Underscoring the commitment to more efficient construction, the UK government has also committed to new standards by 2025, whereby new residential construction must attain a $31 \%$ decrease in carbon emissions from 2021 [42] (Whilst long-term goals challenge firms to develop strategies for reducing emissions by at least 75\% [42]), the short-term considerations for new home construction mandate an immediate change in design and system performance. Performative improvements via offsite construction will allow HAs to not only improve the efficiency of their properties but improve the quality of life (e.g., cost reduction, high-quality residences) for their social applicants, dispelling many lagging stereotypes about social housing and affordable inefficiencies.

Skills, Contracting, and Collaboration: Whereby traditional housing favours designbuild solutions, offsite construction offers the unique opportunity to actively plan, diversify, and integrate modern technologies and structural innovations into a regional design platform [40]. Relying upon advanced, technological skill sets that are steeped in innovation and adaptive design, modern manufactured homes will be developed by skilled workers with advanced degrees, clear visions, and adaptive structural solutions [40].

From local partnerships with HAs to manufacturing innovations and bespoke facility development, these skills transition away from one-off residential development to integrative and modular solutions that can be adapted to systematically improve the process of residential construction.

Speed of Delivery, Systems, and Vision: The case study evidence has confirmed that the rate of project delivery can be accelerated as HAs partner with offsite manufacturing companies to develop solutions that leverage the advantages of modular, prefabricated solutions. From schedule planning for installation to component pre-installation and quality inspections, the responsibilities that once required in-depth on-site scheduling and intensive trades negotiation can now be accomplished in a one-stop facility without requiring multiple streams of coordination and planning [43].

Whereas contractor profit margins were once based upon the gap between trades and contracted rates, offsite solutions increase the cost-material transparency, establishing a new standard of oversight and expense mitigation that can be used to improve the overall cost-performance of offsite initiatives [44]. As HAs are not looking at offsite construction as a one home solution and are targeting larger-scale developments, strategic partnerships with offsite professionals, such as those exemplified by LoCal and Swan, have the potential to significantly improve the overall cost basis of the structural delivery process, eliminating many of the intermediary costs and waste streams that permeate the traditional construction industry.

Figure 7 presents an initial proposal for a more strategic housing association approach to OSC projects.

Through this positive feedback loop, it is suggested that by aggregating demand between housing associations, OSC demonstration projects could be built at sufficient scale to allow cost savings, which would then be monitored, with lessons learned and good practice fed back. Such demonstration projects could gradually increase in scale to meet more of an area's needs and to stimulate further investment in manufacturing capacity. Further, if housing needs could be aggregated, perhaps at the city-region or county level, housing associations could work together with offsite firms, local authorities, and other public sectors to deliver more housing through offsite construction and other technologies. 


\section{Construction Industry Leadership}

Provide guidance on project decision-making process, the site integration of offsite construction methods and better cost data to facilita te more competitive costing.

Embrace the approach 'value for money' rather than 'lowest first cost focus'

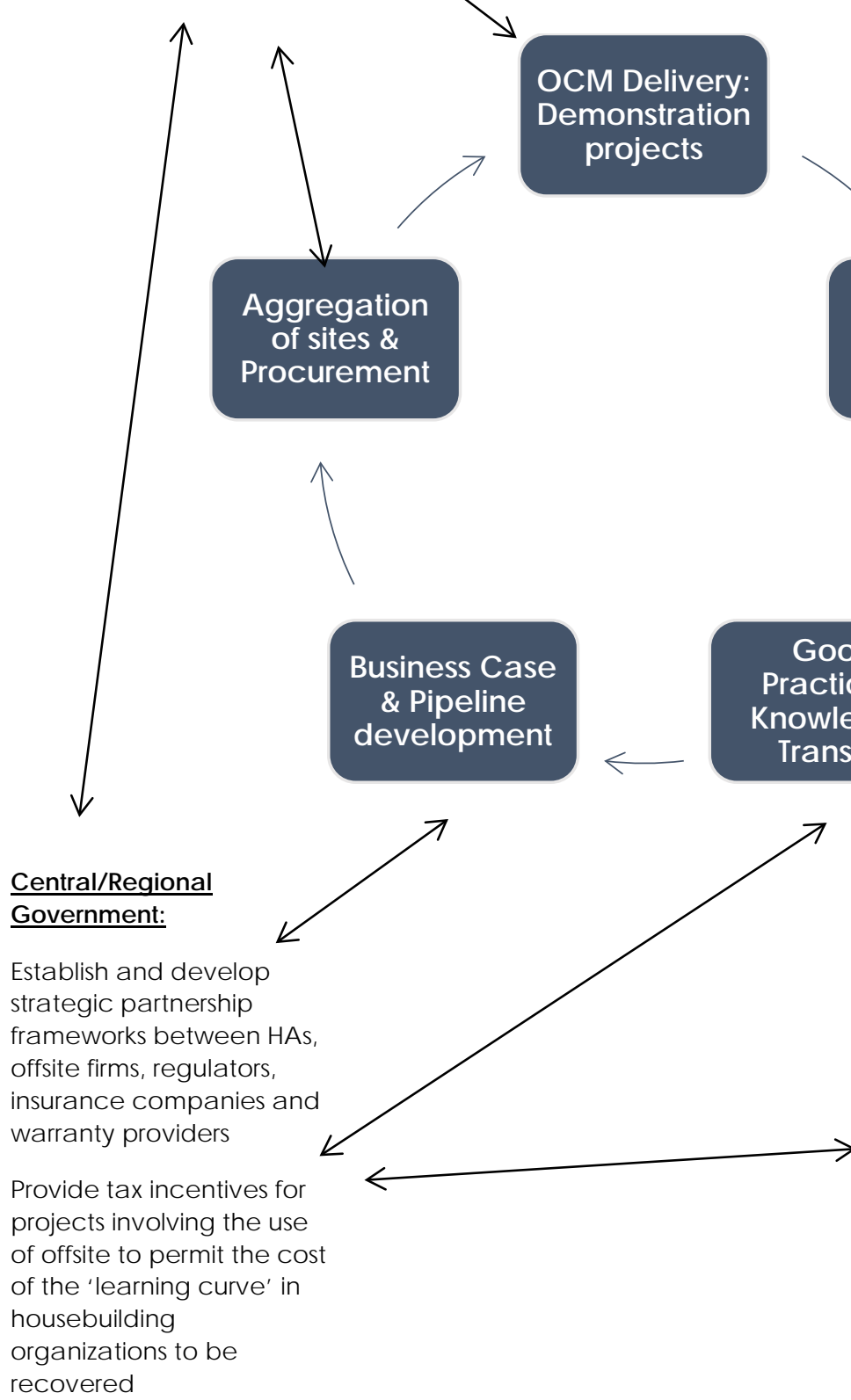

Research/ Monitoring/ feedback

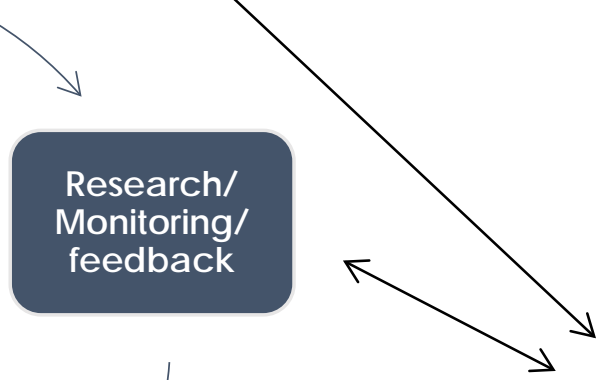

Universities and

Academic Institutions

Establish regional offsite performance centres to test and demonstrate that OSC can deliveras good or better performance than traditional methods

Figure 7. Conceptualized feedback loop for strategic approach for wider adoption of OSC in the HA sector.

This could lead to an OSC sector that becomes more vibrant, robust, thus increasing the resilience of the HA housing sector. In the shorter term, it will allow HAs to build more and higher quality homes that are more energy efficient-providing benefits to their residents and society as a whole.

\section{Strategic Partner Lead}

Integrate manufacturers and suppliers in the project decisionmaking process as early as possible

Facilitate dialogue between housebuilders, housing assoc iations loc al a uthorities 


\section{Conclusions}

This paper has explored HAs' views on the barriers towards the adoption of OSC, how these compare with the perceptions within the wider housing sector, and whether experience in offsite construction methods affects perception towards offsite construction usage. The evidence from this research indicates cost-related barriers are perceived to be the most significant barriers to OSC use for HAs, followed by the capacity of suppliers and end-user preferences for traditional construction. The study was nevertheless limited to the larger HA developers and to HAs with experience of OSC. Consequently, it is not suitable to consider results as representative of all the views of HAs in England, as the perceptions of the sample may differ from HAs with limited experience in relation to OSC. This is an aspect that could be explored through a larger scale, representative study of HAs across England.

To explore whether experience in OSC methods affects perception towards OSC, survey results were analysed based on two subsets: participants with direct experience and those without. The results revealed some noticeable differences between the perceived barriers of the two sample populations. Further, the population with experience were seen to hold stronger opinions. Neither population held perceptions consistently in keeping with the OSC literature. The perceived barriers of those with experience were more aligned with the wider housing sector. Although based on limited sample sizes, this initial exploration indicates that experience does impact perceptions.

The paper proposes that the conceptualised feedback model is proposed to monitor, capture knowledge and share best practices as HAs commit to accelerating project delivery through strategic partnerships with offsite manufacturing firms, local authorities at a local/regional level that leverage the high-value, high-impact transformation of the housebuilding sector in tangible terms of efficiency, cost, and material savings. It is through a coordinated commitment to a unified pursuit of offsite housing throughout a given region or network of housing associations that will ultimately transition this sector from a one-off, bespoke solution approach to one that will support value-added targets of evolving projects.

Funding: This research was funded by the Royal Insituttion of Chartered Surveys Research Trust Project 517: Procurement and contract strategies for offsite manufacturing within UK housebuilding.

Institutional Review Board Statement: The study was conducted in accordance with the Declaration of Helsinki, and approved by the Ethics Committee of the University of Strathclyde.

Informed Consent Statement: Not applicable.

Conflicts of Interest: The author declares no conflict of interest.

\section{References}

1. Offsite Construction in the UK Housing Sector: Barriers and Challenges. Available online: https:/ /journalofindustrializedconstruction. com/index.php/mocs/article/view/23/23 (accessed on 1 February 2022).

2. Charlson, J.; Dimka, N. Design, Manufacture, and Construct Procurement Model for Volumetric Offsite Manufacturing in the UK Housing Sector. Constr. Innov. 2021, 21, 800-817. [CrossRef]

3. Tackling the Under-Supply of Housing in England. Available online: https://researchbriefings.files.parliament.uk/documents/ CBP-7671/CBP-7671.pdf (accessed on 1 February 2022).

4. Ministry of Housing, Communities and Local Government. Modern Methods of Construction Inquiry; GOV.UK: London, UK, 2019.

5. Strategic Plan 2018 to 2023. Available online: https://www.niehs.nih.gov/about/strategicplan/strategicplan20182023_508.pdf (accessed on 1 February 2022).

6. Bramley, G. Housing Supply Requirements Across Great Britain: For Low-Income Households and Homeless People; Crisis: London, UK, 2018.

7. Ministry of Housing, Communities and Local Government. Live Tables on House Building: New Build Dwellings Table 209: Permanent Dwellings Completed, by Tenure and Country; Ministry of Housing, Communities and Local Government: London, UK, 2019.

8. NHF. About Housing Associations. National Housing Federation, 2021; National Housing Federation-About Housing Associations: London, UK, 2021.

9. Oliveira, S.; Burch, J.; Hutchison, K.; Adekola, O.; Jaradat, S.; Jones, M. Making Modular Stack Up: Modern Methods of Construction in Social Housing. Available online: https://core.ac.uk/download/pdf/195265013.pdf (accessed on 1 February 2022). 
10. LoCal Case Studies and Testimonials, Local Homes. Available online: http://www.localhomes.co.uk/case-studies-andtestimonials (accessed on 1 February 2022).

11. Modular Construction, An Innovative Solution to the Housing Industry; Swan Housing Association: London, UK, 2021.

12. Hollander, G. Top 50 Biggest Builders 2019. Available online: https://www.insidehousing.co.uk/insight/insight/top-50-biggestbuilders-2019-62056 (accessed on 1 February 2022).

13. Barratt, L. Top 50 Biggest Builders 2018. Available online: https://www.insidehousing.co.uk/insight/insight/top-50-biggestbuilders-2018-56946 (accessed on 1 February 2022).

14. Rowley, S.; Gilbert, C.; Gurran, N.; Leishman, C.; Phelps, C. The Uneven Distribution of Housing Supply 2006-2016. Australian Housing and Urban Research Institute Limited. Available online: https://www.ahuri.edu.au/sites/default/files/migration/ documents / Executive-Summary-FR334-The-uneven-distribution-of-housing-supply-20062016.pdf (accessed on 1 February 2022).

15. Wehaton, W.C. Real Estate Cycles: Some Fundamentals. Real Estate Econ. 1999, 27, 209-230. [CrossRef]

16. MacAskill, S.; Mostafa, S.; Stewart, R.A.; Sahin, O.; Suprun, E. Offsite Construction Supply Chain Strategies for Matching Affordable Rental Housing Demand: A System Dynamics Approach. Sustain. Cities Soc. 2021, 73, 103093. [CrossRef]

17. NAO. Using Modern Methods of Construction to Build Homes More Quickly and Efficiently. National Audit Office. 2005. Available online: https:/ / www.nao.org.uk/report/using-modern-methods-of-construction-to-build-homes-more-quickly-andefficiently/ (accessed on 1 February 2022).

18. Miles, J.; Whitehouse, N. Offsite Housing Review. Constr. Ind. Counc. 2013. Available online: http://cic.org.uk/download.php?f= offsite-housing-review-feb-2013-for-web.pdf (accessed on 1 February 2022).

19. Barton, C.; Wilson, W. Tackling the Under-Supply of Housing in England; UK Parliament: London, UK, 2021.

20. Kempton, J.; Syms, P. Modern methods of construction: Implications for housing asset management in the RSL sector. Struct. Surv. 2009, 27, 36-45. [CrossRef]

21. Kempton, J. Modern methods of construction and RSL asset management: A quantitative study. Struct. Surv. 2010, 28, 121-131. [CrossRef]

22. Wohlin, C. Guidelines for Snowballing in Systematic Literature Studies and a Replication in Software Engineering. In Proceedings of the 18th International Conference on Evaluation and Assessment in Software Engineering, London, UK, 13-14 May 2014.

23. Housing Market Intelligence Report 2015; Home Builders: London, UK, 2015.

24. Pan, W.; Gibb, A.; Dainty, A. Offsite Modern Methods of Construction in Housebuilding Perspectives and Practices of Leading UK Housebuilders; Buildoffsite: London, UK, 2005.

25. Pan, W.; Gibb, A.; Dainty, A. Perspectives of UK housebuilders on the use of offsite modern methods of construction. Constr. Manag. Econ. 2007, 25, 183-194. [CrossRef]

26. Pinney, R.; Boothman, C.; Higham, A. Main contractor perspectives on the driver for increased offsite manufacture. In Proceedings of the International Research Conference 2017: Shaping Tomorrow's Built Environment Conference Proceedings, Manchester, UK, 12-14 September 2017.

27. Trowers and Hamlins. Modular Construction Is It Time That We Started Taking Modular Construction Seriously? Trowers and Hamlins: London, UK, 2018.

28. NHBC Foundation. Modern Methods of Construction: Who's Doing What? NHBC: Milton Keynes, UK, 2018.

29. NHBC Foundation. Modern Methods of Construction: Views From the Industry; NHBC: Milton Keynes, UK, 2016.

30. Elnaas, H.; Gidad, K.; Ashton, P. Factors and Drivers Effecting the Decision of Using Off-Site Manufacturing (OSM) Systems in House Building Industry. J. Eng. Proj. Prod. Manag. 2014, 4, 51-58. [CrossRef]

31. Alonso-Zandari, S.; Hashemi, A. Prefabrication in the UK housing construction industry. In Proceedings of the 5th International Conference on Zero Energy Mass Customised Housing-ZEMCH 2016, Kuala Lumpur, Malaysia, 20-23 December 2017.

32. Dave, M.; Watson, B.; Prasad, D. Performance and Perception in Prefab Housing: An Exploratory Industry Survey on Sustainability and Affordability. Procedia Engineering, International High-Performance Built Environment Conference-A Sustainable Built Environment Conference 2016 Series (SBE16). Procedia Eng. 2017, 180, 676-686.

33. Pan, W.; Dainty, A.; Gibb, A. Managing Innovation: A Focus on Off-Site Production (osp) in the UK Housebuilding Industry. Available online: https://www.arcom.ac.uk/-docs/proceedings/ar2004-0823-0830_Pan_Dainty_and_Gibb.pdf (accessed on 1 February 2022).

34. Denscombe, M. The Good Research Guide for Small-Scale Social Research Projects, 4th ed.; Open University Press: Maidenhead, UK, 2010.

35. Wright, K. Researching Internet-Based Populations: Advantages and Disadvantages of Online Survey Research, Online Questionnaire Authoring Software Packages, and Web Survey Services. J. Comput. Mediat. Commun. 2005, 10, JCMC1034. [CrossRef]

36. Naoum, S. Dissertation Research and Writing for Construction Students, 3rd ed.; Routledge: London, UK, 2013.

37. Gateshead Innovation Village; Home Group: Gateshead, UK, 2019.

38. Porter, S.R.; Whitcomb, M.E. The impact of contact type on web survey response rates. Public Opin. Q. 2003, 67, 579-588. [CrossRef]

39. Farmer, M. The Farmer Review of the UK Construction Labour Model; Construction Leadership Council: London, UK, 2016.

40. Wallace, A.; Luorio, O.; Simpson, K. Off Site Housing Construction: A Response to the Crisis; University of Leeds: Leeds, UK, 2019.

41. Hopkin, T.; Lu, S.L.; Sexton, M.; Rogers, P. Learning from Defects in the UK Housing Sector Using Action Research: A Case Study of the Housing Association. Eng. Constr. Archit. Manag. 2019, 26, 1608-1624. [CrossRef] 
42. HM Government. Industrial Strategy: Government and Industry in Partnership; HM Government: London, UK, 2013.

43. MHCLG. Rigorous New Targets for Green Building Revolution. Ministry of Housing, Communities, and Local Government. 2021. Available online: www.gov.uk (accessed on 1 February 2022).

44. Vernikos, K. Implementing an Offsite Construction Strategy: A UK Contracting Organisation Case Study. Available online: https:/ / www.researchgate.net/publication/269704441_Implementing_an_Offsite_Construction_Strategy_A_UK_Contracting_ Organisation_Case_Study (accessed on 1 February 2022). 